\title{
Effect of prolonged starvation on the body preoperatively and the role of carbohydrate loading
}

\author{
Abdulkarim Mohammad Alhassoun ${ }^{1 *}$, Fahad Hussain Kammas ${ }^{2}$, \\ Mohammed Yousif Alaissawi ${ }^{3}$, Walaa Mohamed Hasan ${ }^{4}$, Nouf Mohammed Alrabiah ${ }^{5}$, \\ Saja Butti AlHarbi ${ }^{6}$, Othman Mohammed Alshahrani ${ }^{7}$, Anas Sultan Kabli ${ }^{8}$, \\ Sami Abdullah Aljabr', Enass Farouk Aboshoushah ${ }^{10}$, \\ Mohammed Khaled Alanazi ${ }^{11}$, Mohamad Abdulkarim Alhassoun ${ }^{12}$
}

\author{
${ }^{1}$ Department of Anaesthesia, King Faisal Specialist Hospital and Research Center, Jeddah, Saudi Arabia \\ ${ }^{2}$ Department of Emergency Medicine, King Fahad General Hospital, Jeddah, Saudi Arabia \\ ${ }^{3}$ Department of Intensive Care Unit, AlOmran General Hospital, Alahsa, Saudi Arabia \\ ${ }^{4}$ Department of Internal Medicine, King Khalid Hospital, Riyadh, Saudi Arabia \\ ${ }^{5}$ College of Medicine, King Faisal University, Alahsa, Saudi Arabia \\ ${ }^{6}$ College of Applied Medical Sciences, Clinical Nutrition, Imam Abdulrahman Bin Faisal University, Dammam, Saudi \\ Arabia \\ ${ }^{7}$ College of Medicine, Imam Abdulrahman Bin Faisal University, Dammam, Saudi Arabia \\ ${ }^{8}$ Department of Emergency Medicine, East Jeddah Hospital, Jeddah, Saudi Arabia \\ ${ }^{9}$ College of Medicine, Shaqra Medical University, Riyadh, Saudi Arabia \\ ${ }^{10}$ Department of Intensive Care Unit, King Abdulaziz Hospital, Jeddah, Saudi Arabia \\ ${ }^{11}$ Department of Emergency Medicine, Imam Abdulrahman Al Faisal Hospital, Riyadh, Saudi Arabia \\ ${ }^{12}$ College of Medicine, Alfaisal University, Riyadh, Saudi Arabia
}

Received: 30 May 2021

Revised: 13 June 2021

Accepted: 14 June 2021

*Correspondence:

Dr. Abdulkarim Mohammad Alhassoun,

E-mail: dr-ayman-89@hotmail.com

Copyright: (c) the author(s), publisher and licensee Medip Academy. This is an open-access article distributed under the terms of the Creative Commons Attribution Non-Commercial License, which permits unrestricted non-commercial use, distribution, and reproduction in any medium, provided the original work is properly cited.

\begin{abstract}
Although recent reports discourage preoperative overnight fasting, many clinicians and surgeons still recommend 6-8 hours of overnight preoperative fasting before conducting elective surgeries. On the other hand, recent guidelines from worldwide multiple anesthesiology societies have suggested that overnight fasting should be approached with flexible durations and proper techniques. Many complications can result from prolonged fasting and preoperative starvation as the duration of fasting usually lasts for more than 12 hours secondary to intraoperative surgical delays. In this literature review, the aim was to discuss the current evidence from studies in the literature about the effect of preoperative starvation and the effect of carbohydrate $(\mathrm{CHO})$ loading on the clinical outcomes of patients. We have noticed that gastric aspiration and respiratory damage can be prevented by preoperative fasting. However, this can lead to the development of other complications such as insulin resistance, a fierce immune response and exaggerated release of acute-phase reactants which might lead to severe organ damage and worsened patient's prognosis. Accordingly, CHO loading should be carefully approached to properly intervene against these cases to enhance the prognosis of the prospective surgeries and the quality of care for patients.
\end{abstract}

Keywords: Surgery, Fasting, Perioperative, Management, Metabolism 


\section{INTRODUCTION}

Recent evidence-based investigations have reported that reduced preoperative fasting before surgical operations can significantly decrease the morbidity of these patients and reduce the length of hospital stay, depending on multimodal protocols and systemic approaches..$^{1-4}$ Introducing preoperative overnight fasting was done when the anesthetic instruments were still non-advanced to induce gastric emptying and to intervene against the potential adverse events as aspiration and vomiting are leading to respiratory damage. ${ }^{5,6}$ Additionally, overnight fasting was suggested based on a previous investigation that studied respiratory damage following gastric aspiration during anesthesia. ${ }^{7}$ Although recent reports discourage this practice, many clinicians and surgeons still recommend 6-8 hours of overnight preoperative fasting before conducting elective surgeries. ${ }^{6,8}$ On the other hand, recent guidelines from worldwide multiple anesthesiology societies suggest that overnight fasting should be approached with flexible durations and proper techniques. ${ }^{9,10}$

Many complications can result from prolonged fasting and preoperative starvation as the duration of fasting usually lasts for more than 12 hours secondary to intraoperative surgical delays. ${ }^{11}$ Among the reported effects, insulin resistance exaggerated immune response and acute phase reactions have been reported to induce serious damage to the body and multiple organs (Figure 1). ${ }^{12}$ These adverse events can be successfully prevented by $\mathrm{CHO}$ loading which was also reported to be very efficacious in these situations. In this literature review, the aim was to discuss the current evidence from studies in the literature about the effect of preoperative starvation and the effect of $\mathrm{CHO}$ loading on the clinical outcomes of patients.

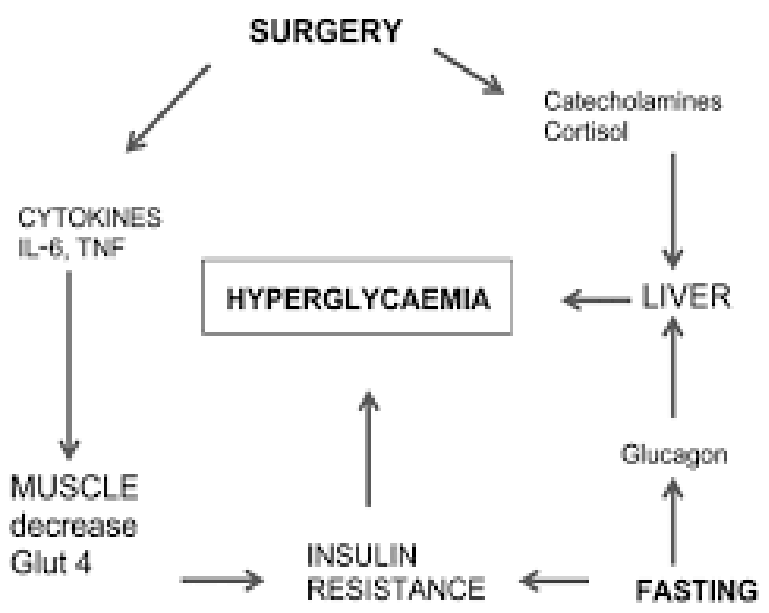

Figure 1: Effect of surgery and preoperative fasting on the postoperative events as insulin resistance and acute phase reactions. ${ }^{46}$

\section{Methodology}

A systematic search was conducted to identify relevant studies in the following databases: PubMed, Medline, Web of Science, Embase, Google Scholar and Scopus. The following search terms were used (prolonged starvation or starvation) and (preoperatively or perioperatively) and (carbohydrate loading). The reference lists were manually searched to identify additional relevant studies meeting inclusion criteria. We included any study that reports effect of prolonged starvation on the body preoperatively and the role of carbohydrate loading. No restrictions were applied.

\section{DISCUSSION}

\section{Gastric aspiration and respiratory damage}

Previous studies have demonstrated the potential development of serious complications that might even be life-threatening. Aspiration and pulmonary damage are two common events that might need urgent interference to enhance the prognosis of the affected patients. Nevertheless, the amount and duration of aspiration is a key factor that determines the severity of the condition and the proper management approaches. A previous investigation by Roberts et al has reported that the acidity of the aspired gastric juice should not be more than 2.5 and the amount of aspiration should be more than $25 \mathrm{ml}$ or $>0.4 \mathrm{ml} / \mathrm{kg}$ to cause aspiration. ${ }^{13}$ However, it has been previously demonstrated that the results of the previous investigation should not be validated in humans because the results were obtained from an investigation that was done on one rhesus monkey. ${ }^{14}$ In the same context, previous investigations that were conducted on other experimental animals also reported a higher limit of aspiration to cause significant pulmonary damage, being $50 \mathrm{ml}$ or $0.8 \mathrm{ml} / \mathrm{kg} .{ }^{15}$ Moreover, although the same findings are hard to be obtained from human investigations, a recent study reported that the standard limit of the aspired gastric contents should not be more than $1.5 \mathrm{ml} / \mathrm{kg}$ to avoid the development of significant pulmonary damage. However, these findings were reported to be limited by the low prevalence and incidence of gastric aspiration in the investigated population. ${ }^{16}$ The prevention of gastric aspiration can be simply achieved by reducing the acidity of the gastric juice and contents. Nonetheless, this cannot be achieved by the administration of water only and it has been demonstrated that pharmacological interventions as the administration of $\mathrm{H} 2$ antagonists can effectively reduce it and alleviate the severity of the condition. ${ }^{17}$ Reducing the gastric volume is also another challenge to reduce the burden of aspiration. Previous investigations have noticed an inverse correlation between the caloric content of the consumed drinks and the process of gastric emptying. For instance, water is the fastest while drinks with an estimated caloric content of $330 \mathrm{kcal}$ are usually slower than other drinks with an estimated caloric content of 220 kcal. ${ }^{18}$ The duration of gastric emptying and fasting has 
also been previously investigated as previous studies have demonstrated that 15 minutes of fasting is an adequately estimated half-life for water to be emptied, while for beef extracts and milk with tea, 20 and 25 minutes have been reported for both, respectively. ${ }^{19,20}$ Therefore, it has been previously suggested that patients should be fasting for at least one hour perioperatively to avoid the development of complications. ${ }^{21}$

\section{Insulin resistance}

Previous studies have demonstrated the potential development of insulin resistance in some patients postoperatively following elective surgeries, which is very high on the first day and might last for up to 2 or 3 weeks and is directly proportional with the severity of traumas that are induced during the surgery. ${ }^{22}$ Insulin resistance usually refers to the presence of an underlying severe metabolic stress and is also an indicator of recovery following elective surgeries. ${ }^{23}$ The appropriate management of serum glucose levels is important for the prognosis of the procedure and the safety of the patients as hyperglycemia might represent a significant risk factor for the development of severe morbidity and might even lead to mortality. ${ }^{24,25}$ Moreover, many factors have been previously reported to affect the development of insulin resistance. These include duration of starvation and preoperative fasting, muscular activities postoperatively, pain management approaches, and the approached surgical techniques during the procedure. ${ }^{26-30}$ Moreover, it is now widely known that insulin resistance can occur preoperatively due to prolonged starvation, which might lead to the development of severe metabolic stress and aggravate the severity of the underlying trauma.

\section{Immune response and acute phase reactions}

Exaggerated fasting and preoperative starvation can significantly induce the release of inflammatory mediators and acute-phase reactants postoperatively. In addition, it has been reported that the administration of CHO-oral supplementations amid the surgery by two or three hours might prevent the development of complications secondary to these events. ${ }^{31,32}$ In a previous randomized double-blinded investigation, Zelić et al included 40 patients that underwent large bowel resection for bowel cancer to find the best way to administer $\mathrm{CHO}$ load and the effect of different three regimens on the postoperative complications. ${ }^{32}$ The authors have reported that the patients were divided into two groups including patients that received oral $\mathrm{CHO}$ two hours before the surgery or the night before it and other patients that did not receive any $\mathrm{CHO}$ oral supplementations. The authors reported that the levels of interleukin-6 (IL-6) were significantly postoperatively lower in the group that received $\mathrm{CHO}$ supplementation. The authors also reported that the postoperative levels of IL-10 significantly increased among patients in the group that received oral CHO drinks amid the surgery. However, the authors reported that none of the study groups had higher rates of complications or prolonged hospital stays following the performed surgeries. Accordingly, it has been previously suggested that the administration of preoperative $\mathrm{CHO}$ drinks can significantly reduce the severity of the inflammatory response and can enhance the prognosis of the surgeries and reduce the frequency of complications. These findings were indicated by a previous metaanalysis which analyzed the results of six studies that included patients that underwent colorectal-cancer-related operations, following the guidelines of the enhanced recovery after surgery multimodal protocol. ${ }^{4}$ Another randomized controlled trial was also conducted within the orthopedic surgical settings to assess the expression of the human leukocyte antigen (HLA)-DR on monocytes and found that the degree and severity of immune response following surgeries were significantly associated with the duration of preoperative starvation and fasting. It was significantly noticed that the expression of the HLA-DR on monocytes was associated with sustained postoperative levels as assessed in patients that received CHO supplementations amid the surgery, while the expression significantly decreased following the surgery in starving patients before the surgery. ${ }^{33}$ In the same context, it was reported that decreased HLA-DR expression on monocytes was significantly associated with increased rates of infections among prospective patients. $^{34}$

Following trauma, inflammation can be significantly present and can be significantly associated with major healing features. However, it has also been previously reported that exaggerated inflammatory reactions can be harmful leading to significant multiple organ damage that might even end up with death. ${ }^{35}$ Many inflammatory mediators can be found circulating the body and within the traumatized area, playing a significant role in tissue repair and healing. Cytokines are one of the commonest inflammatory mediators and acute phase reactants that are frequently observed during these events. Although the actions of cytokines are usually limited to the site of trauma, it has been previously reported that these mediators can pave the way to systematic changes secondary to the presence of trauma. Besides, it has also been observed that cytokines also play a significant role in the release of other inflammatory mediators and acutephase proteins including the $\mathrm{C}$-reactive protein and interleukins. ${ }^{36}$

\section{Role of CHO loading}

Among the significant changes that occur following surgeries, metabolic abnormalities have been previously investigated to play a major part in postoperative pathology. Hyperglycemia, insulin resistance and protein loss have been reported to be the main metabolic postoperative changes that occur secondary to the pituitary and sympathetic stimulation. ${ }^{36}$ It has been reported that some of these changes, especially insulin resistance might worsen the prognosis leading to an increased hospital stay and more frequent mortality 
rates. ${ }^{23,37}$ The role of preoperative $\mathrm{CHO}$ loading is important to enhance the prognosis of post-operative complications and has been extensively reported by many investigations and was primarily noticed in endurance athletes. The potential beneficial role that $\mathrm{CHO}$ loading is mainly attributable to increased stores of muscle glycogen leading to increased performance of muscles during endurance exercises at a rate of $75-80 \%$ of the potential maximum $\mathrm{O}_{2}$ consumption by the same muscles. ${ }^{38-40}$ Ljungqvist et al reported that the effect of insulin resistance can be ameliorated by the overnight administration of intravenous glucose infusions followed by $\mathrm{CHO}$ drinks. ${ }^{41}$ However, it was reported that the clinical benefits from reduced insulin resistance following CHO loading were not significant, although many investigations have reported the potential beneficial role that $\mathrm{CHO}$ administration might play in enhancing postoperative insulin sensitivity. Many studies have been published to assess the effect of CHO loading on patients' outcomes and length of hospital stay. A meta-analysis reported that the effect of $\mathrm{CHO}$ loading was nonsignificant in reducing the length of hospital stay which was 1.08 days for major abdominal surgeries with no apparent benefits for minor or orthopedic surgeries which have been reported to have an expected length of hospital stay that is less than two days. ${ }^{42}$ Another recent meta-analysis reported that the total reduction in hospital stay was even shorter, being only 0.3 days following $\mathrm{CHO}$ loading. However, the same study also found that the benefit with $\mathrm{CHO}$ loading was extended to 1.7 days with major abdominal surgeries. ${ }^{43}$ Another meta-analysis compared the effect of CHO loading with small versus larger doses versus fasting. The authors found that a small reduction of 0.4 and 0.2 days was noticed with the normal and lower doses, respectively, as the authors compared them with fasting. However, no significant reduction was noticed for the two regimens when the authors compared them with placebo or water. ${ }^{44}$ Therefore, it was suggested that the role of $\mathrm{CHO}$ loading is not significant and the estimated reduction in the length of hospital stay among the different investigations might be attributable to other factors as enhanced in-hospital care for these patients. ${ }^{45}$

\section{CONCLUSION}

In this study, it has discussed the different potential effects of preoperative starvation on the postoperative outcomes and the effect of CHO loading on the clinical parameters. Additionally, gastric aspiration and respiratory damage can be prevented by preoperative fasting. However, this can lead to the development of other complications such as insulin resistance, a fierce immune response, and exaggerated release of acute-phase reactants which might lead to severe organ damage and worsened patient's prognosis. Accordingly, CHO loading should be carefully approached to properly intervene against these cases and to enhance the prognosis of the prospective surgeries and the quality of care for patients.
Funding: No funding sources Conflict of interest: None declared

Ethical approval: Not required

\section{REFERENCES}

1. Fearon KC, Ljungqvist $\mathrm{O}$, Von Meyenfeldt $\mathrm{M}$, Revhaug A, Dejong CHC, Lassen K, et al. Enhanced recovery after surgery: a consensus review of clinical care for patients undergoing colonic resection. Clin Nutr. 2005;24(3):466-77.

2. Aguilar-Nascimento JE, Bicudo-Salomão A, Caporossi C, Silva RM, Cardoso EA, Santos TP. Enhancing surgical recovery in Central-West Brazil: The ACERTO protocol results. e-SPEN. 2008;3(2):78-83.

3. Bicudo-Salomao A, Meireles M, Caporossi C, Crotti $\mathrm{P}$, Aguilar-Nascimento J. Impact of the ACERTO project in the postoperative morbi-mortality in a university hospital. Rev Col Bras Cir. 2011;38(1):310.

4. Varadhan KK, Neal KR, Dejong CH, Fearon KC, Ljungqvist O, Lobo DN. The enhanced recovery after surgery (ERAS) pathway for patients undergoing major elective open colorectal surgery: a meta-analysis of randomized controlled trials. Clin Nutr. 2010;29(4):434-40.

5. Warner MA. Is pulmonary aspiration still an important problem in anesthesia? Curr Opin Anaesthesiol. 2000;13(2):215-8.

6. Maltby JR. Fasting from midnight--the history behind the dogma. Best Pract Res Clin Anaesthesiol. 2006;20(3):363-78.

7. Mendelson CL. The aspiration of stomach contents into the lungs during obstetric anesthesia. Am J Obstet Gynecol. 1946;52:191-205.

8. Aguilar-Nascimento JE, Dock-Nascimento DB. Reducing preoperative fasting time: A trend based on evidence. World J Gastrointest Surg. 2010;2(3):57-60.

9. Søreide E, Eriksson LI, Hirlekar G, Eriksson H, Henneberg SW, Sandin R, et al. Pre-operative fasting guidelines: an update. Acta Anaesthesiol Scand. 2005;49(8):1041-7.

10. Smith I, Kranke P, Murat I, Smith A, O'Sullivan G, Søreide E, et al. Perioperative fasting in adults and children: guidelines from the European Society of Anaesthesiology. Eur J Anaesthesiol. 2011;28(8):556-69.

11. Aguilar-Nascimento JE, Perrone F, Assunção Prado LI. Preoperative fasting of 8 hours or 2 hours: what does evidence reveal? Rev Col Bras Cir. 2009;36(4):350-2.

12. Nygren J. The metabolic effects of fasting and surgery. Best Pract Res Clin Anaesthesiol. 2006;20(3):429-38.

13. Roberts RB, Shirley MA. Antacid therapy in obstetrics. Anesthesiology. 1980;53(1):83. 
14. Strunin L. How long should patients fast before surgery? Time for new guidelines. $\mathrm{Br} \mathrm{J}$ Anaesth. 1993;70(1):1-3.

15. Raidoo DM, Rocke DA, Brock-Utne JG, Marszalek A, Engelbrecht HE. Critical volume for pulmonary acid aspiration: reappraisal in a primate model. Br J Anaesth. 1990;65(2):248-50.

16. Putte PVD, Perlas A. The link between gastric volume and aspiration risk. In search of the Holy Grail? Anaesthesia. 2018;73(3):274-9.

17. Maltby JR, Reid CR, Hutchinson A. Gastric fluid volume and $\mathrm{pH}$ in elective inpatients. Part II: Coffee or orange juice with ranitidine. Can J Anaesth. 1988;35(1):16-9.

18. Okabe T, Terashima H, Sakamoto A. Determinants of liquid gastric emptying: comparisons between milk and isocalorically adjusted clear fluids. $\mathrm{Br} \mathbf{J}$ Anaesth. 2015;114(1):77-82.

19. Holt S, Cervantes J, Wilkinson AA, Wallace JH. Measurement of gastric emptying rate in humans by real-time ultrasound. Gastroenterology. 1986;90(4):918-23.

20. Hillyard S, Cowman S, Ramasundaram R, Seed PT, O'Sullivan G. Does adding milk to tea delay gastric emptying? Br J Anaesth. 2014;112(1):66-71.

21. Wilson GR, Dorrington KL. Starvation before surgery: is our practice based on evidence? BJA Ed. 2017;17(8):275-82.

22. Soop M, Nygren J, Thorell A, Ljungqvist O. Stressinduced insulin resistance: recent developments. Curr Opin Clinic Nutrit Metabol Care. 2007;10(2):181-6.

23. Thorell A, Nygren J, Ljungqvist O. Insulin resistance: a marker of surgical stress. Curr Opin Clin Nutr Metab Care. 1999;2(1):69-78.

24. Blixt C, Ahlstedt C, Ljungqvist O, Isaksson B, Kalman S, Rooyackers O. The effect of perioperative glucose control on postoperative insulin resistance. Clin Nutr. 2012;31(5):676-81.

25. Berghe GVD, Wouters P, Weekers F, Verwaest C, Bruyninckx F, Schetz $\mathrm{M}$, et al. Intensive insulin therapy in critically ill patients. $\mathrm{N}$ Engl $\mathrm{J}$ Med. 2001;345(19):1359-67.

26. Thorell A, Nygren J, Essén P, Gutniak M, Loftenius A, Andersson B, et al. The metabolic response to cholecystectomy: insulin resistance after open compared with laparoscopic operation. Eur J Surg. 1996;162(3):187-91.

27. Kanno H, Kiyama T, Fujita I, Tani A, Kato S, Tajiri $\mathrm{T}$, et al. Laparoscopic surgery improves blood glucose homeostasis and insulin resistance following distal gastrectomy for cancer. JPEN J Parenter Enteral Nutr. 2009;33(6):686-90.

28. Greisen J, Juhl CB, Grøfte T, Vilstrup H, Jensen TS, Schmitz O. Acute pain induces insulin resistance in humans. Anesthesiology. 2001;95(3):578-84.

29. Biensø RS, Ringholm S, Kiilerich K, AachmannAndersen N, Krogh-Madsen R, Guerra B, et al. GLUT4 and glycogen synthase are key players in bed rest-induced insulin resistance. Diabetes. 2012;61(5):1090-9.

30. Faria MS, Aguilar-Nascimento JE, Pimenta OS, Alvarenga LC, Dock-Nascimento DB, Slhessarenko N. Preoperative fasting of 2 hours minimizes insulin resistance and organic response to trauma after video-cholecystectomy: a randomized, controlled, clinical trial. World J Surg. 2009;33(6):1158-64.

31. Viganò J, Cereda E, Caccialanza R, Carini R, Cameletti B, Spampinato M, et al. Effects of preoperative oral carbohydrate supplementation on postoperative metabolic stress response of patients undergoing elective abdominal surgery. World $\mathbf{J}$ Surg. 2012;36(8):1738-43.

32. Zelić M, Stimac D, Mendrila D, Tokmadžić VS, Fišić E, Uravić M, et al. Influence of preoperative oral feeding on stress response after resection for colon cancer. Hepatogastroenterology. 2012;59(117):1385-9.

33. Melis GC, Leeuwen PAV, Flier BMEVD, GoedhartHiddinga AC, Uitdehaag BMJ, Schijndel RJMSV, et al. A carbohydrate-rich beverage prior to surgery prevents surgery-induced immunodepression: a randomized, controlled, clinical trial. JPEN J Parenter Enteral Nutr. 2006;30(1):21-6.

34. Hershman MJ, Cheadle WG, Wellhausen SR, Davidson PF, Polk HC. Monocyte HLA-DR antigen expression characterizes clinical outcome in the trauma patient. Br J Surg. 1990;77(2):204-7.

35. Aguilar-Nascimento JE, Marra JG, Slhessarenko N, Fontes CJ. Efficacy of national nosocomial infection surveillance score, acute-phase proteins, and interleukin- 6 for predicting postoperative infections following major gastrointestinal surgery. Sao Paulo Med J. 2007;125(1):34-41.

36. Desborough JP. The stress response to trauma and surgery. Br J Anaesth. 2000;85(1):109-17.

37. Sato H, Carvalho G, Sato $T$, Lattermann R, Matsukawa T, Schricker T. The association of preoperative glycemic control, intraoperative insulin sensitivity, and outcomes after cardiac surgery. J Clin Endocrinol Metab. 2010;95(9):4338-44.

38. Bergström J, Hermansen L, Hultman E, Saltin B. Diet, muscle glycogen and physical performance. Acta Physiol Scand. 1967;71(2):140-50.

39. Pizza FX, Flynn MG, Duscha BD, Holden J, Kubitz ER. A carbohydrate loading regimen improves high intensity, short duration exercise performance. Int $\mathbf{J}$ Sport Nutr. 1995;5(2):110-6.

40. Tarnopolsky MA, Atkinson SA, Phillips SM, MacDougall JD. Carbohydrate loading and metabolism during exercise in men and women. $\mathrm{J}$ Appl Physiol. 1995;78(4):1360-8.

41. Ljungqvist $\mathrm{O}$, Thorell A, Gutniak M, Häggmark T, Efendic S. Glucose infusion instead of preoperative fasting reduces postoperative insulin resistance. J Am Coll Surg. 1994;178(4):329-36.

42. Awad S, Varadhan KK, Ljungqvist O, Lobo DN. A meta-analysis of randomised controlled trials on 
preoperative oral carbohydrate treatment in elective surgery. Clin Nutr. 2013;32(1):34-44.

43. Smith MD, McCall J, Plank L, Herbison GP, Soop M, Nygren J. Preoperative carbohydrate treatment for enhancing recovery after elective surgery. Cochrane Database Syst Rev. 2014;8:009161.

44. Amer MA, Smith MD, Herbison GP, Plank LD, McCall JL. Network meta-analysis of the effect of preoperative carbohydrate loading on recovery after elective surgery. Br J Surg. 2017;104(3):187-97.

45. Tewari N, Awad S, Duška F, Williams JP, Bennett A, Macdonald IA, et al. Postoperative inflammation and insulin resistance in relation to body composition, adiposity and carbohydrate treatment:
A randomised controlled study. Clin Nutr. 2019;38(1):204-12.

46. Pillinger NL, Robson JL, Kam P. Nutritional prehabilitation: physiological basis and clinical evidence. Anaesth Intensive Care. 2018;46(5):45362.

Cite this article as: Alhassoun AM, Kammas FH, Alaissawi MY, Hasan WM, Alrabiah NM, AlHarbi $\mathrm{SB}$, et al. Effect of prolonged starvation on the body preoperatively and the role of carbohydrate loading. Int J Community Med Public Health 2021;8:3618-23. 